\title{
Saqueos, saqueadores y espacialidad: Memorias del 2001 en sectores populares del Gran Buenos Aires
}

\author{
Looting, Looters, and Spaces: Memories of 2001 in Popular Areas of Greater \\ Buenos Aires
}

\section{Saqueios, saqueadores e espacialidade: memórias de 2001 nos setores populares da Grande Buenos Aires}

\author{
Javier Nuñez \\ javiern1991@gmail.com \\ Universidad de Buenos Aires, Instituto de \\ Investigaciones Gino Germani, \\ Consejo Nacional de Ciencia y Técnica, Argentina
}

Recepción: 02 Octubre 2020

Aprobación: 19 Abril 2021

Publicación: 01 Diciembre 2021
Resumen: Las memorias del 2001 en los sectores populares del Gran Buenos Aires se enfocan en los saqueos de diciembre y, en especial, en los rasgos de quién participó de ellos. Así, pueden ser estudiadas como desplazamientos en términos de proximidades y distancias respecto a la figura del saqueador. Si bien todos los entrevistados comparten una representación de dicha figura bajo el predominio de la lejanía, las modalidades de elaboración de esta memoria se encuentran segmentadas según el impacto de la crisis en la trayectoria laboral del sujeto y los usos del espacio local.

Palabras clave: Crisis, 2001, Memorias, Saqueos.

Abstract: The memories of the 2001 Argentine crisis in popular sectors of the Greater Buenos Aires concentrate on the December lootings and, especially, on the features of those who took part of them. As a result, those memories may be studied in terms of proximities and distances in relation to the representation of the looter. Although all interviewees describe that figure from a predominantly distant position, the elaboration of that memory is segmented depending on the impact of that crisis on the subject's labor trajectory and the uses of local space.

Keywords: Crisis, 2001, Memories, Looting.

Resumo: As memórias de 2001 nos setores populares da Grande Buenos Aires se focam nos saqueios de dezembro e, especialmente, nas características daqueles que participaram deles. Desse modo, podem ser estudados como deslocamentos em termos de proximidades e distâncias em relação à imagem do saqueador. Embora todos os entrevistados compartilham uma representação dessa imagem sob o predomínio do afastamento, as modalidades da elaboração dessa memória se encontram segmentadas segundo o impacto da crise na trajetória laboral do sujeito e dos usos do espaço local.

Palavras-chave: Crise, 2001, Memórias, Saqueios. 


\section{INTRODUCCIÓN}

La crisis del 2001 reunió una serie de procesos complejos, simultáneos, articulados e incluso contradictorios entre sí: desde el declive económico que marcó el final estruendoso de la convertibilidad, la renuncia sucesiva de varios presidentes y la realización de acciones colectivas de diversos formatos, desplegadas en especial durante el mes de diciembre y los primeros meses del año siguiente. Ahora bien, como acontecimiento que es objeto de rememoración, el 2001 recibió diversos significados y evocaciones. Para los sectores populares del Gran Buenos Aires, los saqueos del mes de diciembre suponen una referencia ineludible.

La importancia que adquirieron los saqueos desde la crisis de 1989 no es ajena a los cambios en la cuestión social provocados por las reformas neoliberales, así como de las políticas que el Estado emprendió como respuesta al creciente empobrecimiento de los sectores populares (Merklen, 2010; Serulnikov, 2017). Sin embargo, como acontecimiento, implicaron un hecho fuertemente disruptivo, imponiendo, en quienes lo vivieron, la necesidad de otorgarle un sentido. Interrogarse por la elaboración de su memoria supone indagar las formas en que se tematiza esta interrupción de la vida cotidiana y se la inscribe en un conjunto de representaciones sociales.

Tal como se desarrollará en este artículo, la memoria de los saqueos se articula antes en el saqueador que en el suceso mismo: la evaluación -no exenta de categorizaciones morales- de quienes protagonizaron el saqueo constituye el núcleo del trabajo de evocación. La personificación del saqueador -el modo en que se lo significa- no se presenta, empero, encapsulado: se vincula al sentido dado al contexto de crisis económica y al anclaje del saqueo en el espacio local del barrio. La figura del saqueador, su acción en un contexto de crisis y el espacio en que se desarrolla el saqueo conforman tres dimensiones que posibilitan el abordaje de una memoria concentrada en dicha figura.

En consecuencia, su elaboración por parte de los sectores populares del Gran Buenos Aires puede ser descripta a partir de diferentes desplazamientos en términos de proximidades y distancia con el saqueador, que definen qué tan aceptable, legítima resulta esa acción. Ahora bien, esta operación simbólica no permite cualquier posibilidad: las variaciones en el posicionamiento respecto al saqueador se enmarcan, siempre, en el predominio de la lejanía por sobre la proximidad.

El sentido dado a esta distancia -su profundización o su matiz-involucra dos segmentaciones. Por un lado, el impacto socio-económico de la crisis del 2001 en la trayectoria laboral (personal o familiar) de quien recuerda. Segundo, los usos del espacio local, desde exclusivamente individual/familiares hasta la participación en organizaciones territoriales. Estas variables dialogan con dos de las dimensiones anteriores el sentido dado al contexto de crisis y al anclaje espacial del saqueo- y configuran una valoración más o menos distanciada en relación al saqueador.

Para analizar estas memorias se han seleccionado a dos barrios del Municipio de Quilmes -El Tala y Alicia Esther-como caso de estudio. Se ubican en la zona de San Francisco Solano y en los comercios cercanos ocurrieron saqueos en el 2001. El objetivo general se propone comprender las memorias de habitantes del Gran Buenos Aires acerca de los saqueos del 2001 según el impacto de la crisis en las trayectorias laborales de los sujetos y los usos que realizan del espacio del barrio. Para arribar a tal objetivo, se postulan otros tres, de rango específico. Primero, describir la memoria del impacto socio-económico de esta crisis. Segundo, dar cuenta del sentido dado al anclaje espacial de los saqueos. Tercero, conocer la representación de quien participó de los saqueos.

La hipótesis que ordenará el análisis de estas memorias indica que el impacto laboral de la crisis y los usos del espacio local favorecen desplazamientos en términos de proximidades y distancias en relación a la figura representada del saqueador, si bien siempre bajo el predominio de la lejanía. Quienes padecieron situaciones de desempleo durante la crisis y tienen usos colectivos del espacio a partir de la participación en organizaciones territoriales tenderán a matizar ese distanciamiento. En cambio, aquellos que no cumplan esas dos condiciones personificarán al saqueador acentuando la lejanía con él. 
El artículo se integra de cinco partes. Luego de algunas precisiones históricas y de orden teóricometodológico, se desarrollan tres grandes perfiles de entrevistados, según qué tanto profundizan el distanciamiento respecto a quién participó de los saqueos.

\section{EL 2001: CRISIS, MOVILIZACIONES Y SAQUEOS}

La crisis del 2001 constituyó la clausura explosiva de un cuarto de siglo caracterizado por la aplicación casi ininterrumpida de políticas económicas de corte neoliberal. Hacia fines de ese año, la continuidad de la Convertibilidad había devenido insostenible de la mano de un inédito endeudamiento, al que se sumó la renuncia anticipada de varios gobiernos y fuertes pujas entre facciones de sectores dominantes (Basualdo, 2011). Esos elementos - desde la crisis cambiaría y de deuda hasta sus componentes sociales y políticos- ya habían tenido un antecedente en la crisis de 1989, que daría lugar a una veloz profundización del modelo neoliberal (Basualdo, 2011).

Si bien el 2001 puede ser pensado a partir de numerosas dimensiones, para estudiar las memorias de los sectores populares resultan centrales las formas de movilización ocurridas en ese momento y, en particular, los saqueos.

La crisis se caracterizó por la coexistencia de diversos tipos de acciones colectivas, de diferente temporalidad. Dichas acciones pueden englobarse en tres grandes conjuntos: primero, piquetes y manifestaciones de trabajadores desocupados; segundo, cacerolazos, asambleas y manifestaciones de ahorristas; tercero, saqueos (Pereyra, 2008).

Los piquetes y organizaciones de desocupados habían surgido a mediados de los años 90', con un especial crecimiento en Buenos Aires a partir del año 1998, de la mano de diferentes organizaciones sociales y políticas (Svampa y Pereyra, 2003). Ya se habían producido cacerolazos repetidas veces durante la década de 1990 pero las asambleas y los movimientos de ahorristas tuvieron su pico en los últimos meses del 2001 y la primera mitad del año siguiente (Pereyra, 2008). Los saqueos, en cambio, tuvieron una temporalidad más veloz y breve: empezaron el 12 de diciembre y crecieron con fuerza a partir del 16. Dos días después, se generalizaron en el conurbano bonaerense, al tiempo que se extendieron los pedidos de alimentos a supermercados. La existencia de estas solicitudes parece haber sido confundida en muchos casos con saqueos, magnificando la capacidad de propagación de los rumores (Schuster et al, 2002). Finalmente, los episodios más importantes -junto con represiones policiales- ocurrieron en el Gran Buenos Aires y en Rosario, con sucesos similares en otras provincias y ciudades de importancia. ${ }^{1} \mathrm{El}$ número total de acciones -incluyendo pedidos de alimentos y saqueos- habría rondado los 600 (Gordillo, 2017).

La faceta político-institucional de la crisis, los acontecimientos que dieron lugar a las sucesivas renuncias presidenciales, así como el desarrollo del movimiento de trabajadores desocupados o las formas de participación asamblearias de principios del 2002, entre otras cuestiones, han recibido una considerable atención académica (Ozarow, Levey y Wylde, 2016). Sin embargo, no tuvieron necesariamente la misma importancia en las memorias elaboradas por los sectores populares del conurbano bonaerense que, como se desarrollará en el caso seleccionado, tienden a concentrarse en los saqueos de diciembre del 2001.

De esos tres conjuntos de acciones, los saqueos también habían tenido un claro antecedente en 1989, impactando sobre las sociabilidades barriales, en especial entre territorios (Prevot-Schapira, 2009). Empero, estuvieron lejos de constituir una total innovación: exhibieron los cambios estructurales ocurridos desde la mitad de los años 70' y se inscribieron en el creciente empobrecimiento, así como en formatos previos de reclamo social (Serulnikov, 2017). De esta manera, pueden ser comprendidos como parte de una "nueva cuestión” social (Serulnikov, 2017; Merklen, 2010).

Los saqueos del 2001 despertaron mayor interés académico, regresando sobre los del 80' en la clave de un anticipo (Auyero, 2007, Prevot-Schapira, 2009). Las investigaciones acerca de estas dinámicas han resaltado el rol jugado por ciertas "relaciones clandestinas" -en especial entre saqueadores, policías e hipermercados- 
en su origen (Auyero, 2007) o en su organización y control (Ossona, 2017). Esta "zona gris" alumbra la continuidad de prácticas políticas relativamente cotidianas en un hecho extraordinario como es el saqueo. Si bien algunas trabajos han convertido a los vínculos con ciertos ilegalismos -y entramados partidarios- en un factor eminente para describir la organización de los saqueos (Ossona, 2017), también se ha señalado su dimensión de acción colectiva y su vínculo con una representación mínima de derechos no garantizados por el Estado (Gordillo, 2017), superando a la acción de grupos organizados, en un clima de total superación de los diques de contención social (Serulnikov, 2017). Además, se ha remarcado la importancia del rumor en su circulación y en la memoria construida con posterioridad a esos sucesos (Neufeld y Cravino, 2007). Sin embargo, hasta el momento han sido escasos los trabajos académicos que se focalicen propiamente en la memoria de los saqueos (Serulnikov, 2017; Onuch, 2016), en especial en la que no fue elaborada en los meses o años posteriores al 2001.

Como se mencionó, dos barrios lindantes - Alicia Esther y El Tala-ubicados en San Francisco Solano, Municipio de Quilmes, fueron escogidos como caso de estudio. Estos territorios contienen numerosas similitudes, al punto de que, en la observación directa, no pueden notarse contrastes en términos de su grado de consolidación. No obstante, fueron el producto de historias bien diferentes. Alicia Esther surgió a través de un loteo popular de los años 60', que no estuvo exento de ciertas irregularidades. En cambio, El Tala fue fundado en el contexto de una serie de ocupaciones de tierra de fines de 1981, que inauguraron cierto formato de acción colectiva y que, en la clave de una toma clásica, ha sido profusamente estudiado desde los años 80' (Izaguirre y Aristizabal, 1988). Los cambios en las organizaciones de los asentamientos ocurridos a partir de los 90’ -como su creciente rol de mediadores en la implementación de políticas públicas o una mayor imbricación con estructuras partidarias (Merklen, 2010)- tuvieron particular énfasis en las "tomas" de San Francisco Solano. Las diferencias entre barrios facilitaron contar con una muestra de entrevistados que diera cuenta de trayectorias laborales y de politicidad popular diversas entre sí que no es ajena a la evocación de lo ocurrido en el 2001.

La zona no fue ajena a los saqueos del 2001. Los comercios de la avenida Donato Álvarez -que separa al Municipio de Quilmes del de Almirante Brown, lindante con Alicia Esther- fueron saqueados, al igual que otras áreas comerciales de la zona. Esta arteria constituye una zona comercial de cierta importancia, aunque se encuentra a varias cuadras del centro de San Francisco Solano -además de estar apartada de la cabecera del municipio. Los relatos de los entrevistados permitieron reconocer que el saqueo incluyó a supermercados de tamaño mediano, así como a carnicerías y frigoríficos de pequeña escala. La respuesta policial parece haber sido esporádica, incluyendo hechos de represión.

\section{De LA CONSTRUCCión DE LA MEMORIA DEL SAQUEO A SU ESPACIALIDAD: ALGUNAS PRECISIONES TEÓRICAS Y METODOLÓGICAS}

Las memorias conforman, como cualquier otra simbología, una representación social. Su producción transforma ciertos elementos de la realidad social en núcleos de sentido - proceso denominado objetivaciónque se encuentran en relación con otras construcciones de sentido, con las que dialogan y que participan de la formación de esos núcleos -anclaje (Jodelet, 1984). En este proceso, la información que permite significar cierto objeto se articula bajo modalidades complejas con su valoración, usualmente pensada en términos del posicionamiento o actitud del sujeto. Representaciones con una fuerte carga moral, como las que atraviesan las memorias de los saqueos, resaltan la proximidad o distancia que el enunciador establece en relación a aquello que describe -en este caso, la acción de los saqueadores.

Siguiendo este camino, bien podría plantearse que las memorias del 2001, aún si están provistas de una temporalidad pasada, resultan comprensibles a la luz de las significaciones del presente y que, entre estas, destacan aquellas que remiten a categorizaciones morales (en el decir de Thompson, 1979). Por caso, el saqueo no deja de constituir un acto ilegal y el predominio de una memoria fuertemente deslegitimante del mismo 
prueba el peso de las nociones que definen aquello que resulta aceptable -y que no- en la construcción de la memoria. De esta manera, la evocación de los saqueos involucraría diversos anclajes, que remiten a núcleos de sentido que exceden lo específico del acontecimiento: legitimidades referidas a acciones colectivas, figuras que remiten a diferentes formas de inseguridad, a la policía o a los comerciantes con establecimiento de diferente tamaño, además de otras memorias sobre la Argentina reciente.

Ahora bien, esta modalidad de construcción de la memoria no puede ser abordada al margen de la experiencia del 2001 en barrios populares del Gran Buenos Aires. La memoria no supone solo una representación desde el presente sino la modificación (Ricoeur, 2004) de ciertos recuerdos bajo narraciones que permiten inscribirlos en un sentido. En efecto, los habitantes de zonas en los que ocurrieron saqueos o por lo menos el rumor hizo que su posibilidad pareciera inminente- se encontraron frente a un hecho que interrumpió fugaz y violentamente la vida cotidiana, imponiendo el esfuerzo de encontrarle un significado. Como indica Jelin, "las rupturas en esas rutinas esperadas involucran al sujeto de manera diferente. Allí se juegan los afectos y sentimientos que pueden empujar a la reflexión a la búsqueda de sentido" (Jelin, 2002, p. 27). Por tanto, si la figura del saqueador -y la distancia respecto a él- ocupan un rol central en la elaboración del recuerdo, dicha construcción no puede ser pensada al margen de una experiencia particular, en la que quien rememora se coloca a sí mismo como testigo de los saqueos, estableciendo una particular participación en los mismos -secundaria pero desde la posición de observador.

Así, se presenta una dualidad en la memoria de los saqueos, dada por un conjunto de construcciones de sentido y por su experiencia específica. Ambos planos participan de la evocación: así cómo la experiencia impone la necesidad de darle sentido, reconstruyendo la memoria narrativa, la articulación entre representaciones sociales aporta elementos que serán colocados en el centro de la memoria, reconstruyendo lo sucedido.

Los diferentes posicionamientos que el sujeto establece en relación a los saqueadores dan cuenta de modalidades disímiles de construcción de esa memoria. Al respecto, dos segmentaciones resultan de especial importancia: el impacto de la crisis en la trayectoria laboral y los usos del espacio.

La "centralidad del trabajo" (Castel, 2010), su carácter ordenador de las trayectorias de los sujetos aún en contextos de su debilitamiento, puede ser reconocida en la importancia del impacto socio-económico de la crisis en la definición de sus memorias. La evocación del 2001 guarda diferencias según el entrevistado haya estado desempleado o la crisis lo afectó principalmente en términos de falta de circulante o pérdida de poder adquisitivo. Al mismo tiempo, como toda reconstrucción de lo sucedido, el recuerdo de esta faceta del 2001 no es ajeno a otras construcciones de sentido del presente, incluyendo algunas que marcan proximidades y distancias respecto a otros vecinos en el 2001 y en la actualidad. Como se verá, ambos planos -el de la experiencia y el de la representación- inciden sobre la tematización del saqueador así como sobre consideraciones generales sobre cómo impactaron las dificultades económicas.

La dimensión espacial no define solo un escenario del recuerdo, como si fuera asimilable al espacio físico como contenedor de lo ocurrido. La espacialidad cumple un rol en la memoria a través del vínculo que cada sujeto tiene con el territorio en que se desarrolla su vida cotidiana. Resaltando la importancia de la localización del recuerdo, Halbwachs decía que el espacio auxiliaba a la reconstrucción en tanto era una "realidad que dura" (Halbwachs, 2004). Lejos de ser un continuo cartesiano, extendido linealmente desde cada conciencia, la espacialidad implica la existencia de un sitio apropiado, modelado según la acción, los usos, jerarquías y las representaciones que de él se construyan (Lefebvre, 2013). Participa de la formación de memorias, brindando parcialmente sus condiciones de posibilidad, así como el sentido que se le aporta al anclaje espacial del pasado no es ajeno a otras representaciones. La ubicación del saqueo como un hecho ocurrido -o no- en el espacio local resulta central en relación a la definición de aquellos rasgos que hacen al saqueador.

Ahora bien, por más que la conformación del barrio como espacio apropiado juega un papel fundamental en la elaboración de la memoria del 2001, esta apropiación guarda variaciones según los usos que se realizan 
de la espacialidad, junto con su consecuente apropiación. A grandes rasgos, el empleo colectivo del espacio a partir de la participación en organizaciones ancladas localmente favorece una memoria que resalta al saqueo como un hecho ocurrido en el barrio, aproximando al saqueador al punto de vista de quien evoca lo sucedido. Las modalidades territorializadas de intervención estatal fomentadas desde los 90' inscribieron a la politicidad popular en el espacio local (Merklen, 2010). Así como esta "nueva cuestión social" no fue ajena al desarrollo de los saqueos (Serulnikov, 2017), tampoco lo es a las trayectorias de los entrevistados.

Estos dos planos -laboral y espacial- segmentan a los entrevistados al tiempo que refieren a dos de las dimensiones que hacen a la memoria del 2001 en sectores populares del Gran Buenos Aires. El impacto socio-económico de la crisis y el anclaje espacial del saqueo, junto con la personificación del saqueador, permiten operacionalizar dicha memoria y reconocer las variables ${ }^{2}$ que generan modalidades de evocación diferenciadas. Como se anticipó, esos modos de elaboración del recuerdo remiten, antes que nada, a la proximidad o distancia respecto a la figura del saqueador.

Para la realización del trabajo de campo se realizaron entrevistas semi-estructuradas de forma colectiva, en el marco del seminario de la Carrera de Sociología (UBA) "Movimientos sociales y procesos de (des)encaje: reconfiguraciones de las identidades colectivas". ${ }^{3}$ Las entrevistas fueron realizadas en los barrios El Tala $y$ Alicia Esther en noviembre del 2015, llevándose a cabo 13 de ellas. La muestra siguió cuotas de edad y género. Se entrevistaron vecinos que circulaban por el lugar, sin contacto previo con ellos.

Durante el análisis, además, se establecieron otras segmentaciones, prestando atención a las variables de interés. Primero, se diferenció a los entrevistados según cómo su trayectoria laboral fue afectada por la crisis del 2001, categorizándolos según si habían atravesado -en persona o vía su familia más cercanasituaciones de desempleo, si habían recurrido a trabajos eventuales frente al descenso del poder adquisitivo o sí solo habían tenido dificultades para conseguir dinero en efectivo. Segundo, los usos del espacio barrial fueron categorizados en individual-familiares (con distintos grados) y colectivos. Estos últimos remiten a la integración de organizaciones locales. Para reconocerlos, se prestó atención a la participación de los entrevistados en políticas sociales o en ocupaciones de tierra -que reiteradamente se desarrollan en la zona desde los 80'. Una descripción exhaustiva de estos usos excede a los objetivos de este trabajo y se ha optado por desarrollar sus vinculaciones con las modalidades de evocación de los saqueos del 2001.

Para el desarrollo de estas formas divergentes de elaboración de memoria, se confeccionaron tres perfiles de entrevistados, según la proximidad o distancia que establecen respecto al saqueador. Para la exposición de estos perfiles, se seleccionó un entrevistado que exhibiera los rasgos típicos de cada memoria. El primer perfil da cuenta de un entrevistado cuya trayectoria laboral no estuvo atravesada por el desempleo en el 2001 y que no lleva a cabo usos colectivos del espacio local. En cambio, el segundo perfil está representado por una entrevistada cuyos familiares directos se encontraban desempleados, pero mantiene una apropiación del espacio local eminentemente individual/familiar. Finalmente, la tercera entrevistada fue afectada fuertemente por la crisis y su participación en organizaciones territoriales favoreció a una apropiación colectiva del espacio local.

\section{De la ausencia a La Distancia matizada: MEMORias DEL SAQUEAdor y SU ESPACIALIDAD}

\subsection{Ni crisis ni saqueadores: la memoria expulsada del espacio local}

Juan Carlos, ${ }^{4}$ de 59 años al momento de la entrevista, trabajó durante tres décadas en la construcción, antes de jubilarse anticipadamente por un problema de salud, apenas un año antes de la entrevista. Fue empleado de varias empresas y su trayectoria está marcada por cierta estabilidad, dada por una condición de formalidad prolongada. Su jornada laboral suponía la salida diaria del barrio, usualmente hacia Capital o zonas céntricas 
del Conurbano. Se aproxima al perfil de un trabajador estable, para quien la periferia urbana cumple cierta función estereotipada de "ciudad-dormitorio", tan cara a los estudios urbanos de mediados de siglo pasado. Estas vinculaciones con lo laboral y lo espacial brindan un punto de partida desde donde comprender la memoria que elabora del 2001.

Cuando se le pregunta acerca del componente socio-económico de esa crisis, Juan Carlos construye una descripción que lo sitúa en ese contexto tanto como lo aparta:

Ya te digo, por ejemplo, acá las crisis se las toma... Bah, nosotros lo hemos tomado gracias a dios, con calma, sin desesperación, sin nada. Con calma, vivíamos día a día, pero bien, ¿me entendés lo que te quiero decir? Nosotros no éramos una persona de decir: "Uy, mirá, se va a terminar el azúcar". Y salir corriendo a comprar azúcar, comprar yerba. "No, no, pará, calmate". Pará (...) Se vivía en la desesperación todo el mundo. La desesperación... Eso es lo que pasó; pero no, nosotros gracias a Dios, ya te digo (...) Si el mundo sería [fuera] tres como yo. (Juan Carlos, jubilado, 59 años).

El relato puede parecer un tanto extraño si se tiene en cuenta el momento culmine del 2001, con una crisis que involucraba desde la falta de dinero en efectivo hasta renuncias presidenciales. Sin embargo, la representación de Juan Carlos suele estar presente entre quienes no perdieron su empleo en ese momento y construyen una memoria de los 90' marcada por una estabilidad laboral conservada en tiempos de creciente desempleo.

Dos elementos del fragmento anterior anticipan la mirada sobre el saqueador: la descripción de esa coyuntura, por un lado; el distanciamiento del enunciador respecto a ese contexto. La crisis adquiere un sentido tanto generalizado como parcial; su actitud frente al momento es de espera y esfuerzo personal -de superación del día a día. En cambio, cierta heterogeneidad subyace a la cita, construyendo una perspectiva alterna de quien no se mantiene tranquilo frente al momento y a quien Juan Carlos le pide -explícitamentecalma. El resultado es cierta construcción de distinción, tematizada -al finalizar- mediante la definición de los rasgos propios como universalmente deseables.

Esta evocación de la crisis entraña un punto de vista particular, magnificado discursivamente en el fragmento: al adjudicarse su templanza, Juan Claros se configura a sí mismo como un observador apartado. Al mismo tiempo, la anécdota que relata no es ajena al recuerdo de otros acontecimientos similares: la posible falta de alimentos (azúcar y yerba, en este caso) recuerda a la hiperinflación del 89' antes que al 2001 aunque también establece un tipo de expectativa en torno a las características de esos momentos (la falta de productos de primera necesidad). Así, esta memoria resalta por las distancias con la literatura que ha focalizado el estudio del 2001 en su faceta político-institucional: mínimamente, indica como la crisis puede ser inscripta en una expectativa de situaciones semejantes, provistas de ciertos caracteres típicos, incluso rutinarios.

Esta experiencia de la crisis no adquiere, empero, rasgos colectivos, comunes a los demás; por el contrario, está marcada por una frontera entre lo individual/familiar (acá las crisis se las toma con calma) y otras personificaciones más lejanas, con las que potencialmente se interactúa aunque viven la crisis de otra manera. El resultado es la definición del modo legítimo de atravesar ese contexto, caracterizado por la espera y la tranquilidad en contraposición tajante con la desesperación y la acción repentina.

Este punto de partida -la crisis como un suceso palpable tanto como medianamente lejano- rodea a los saqueos: los sitúa en un momento histórico, colocándolos en una trama que les brinda sentido. No es de extrañar, entonces, que el entrevistado los ubique en sitios lejanos, expulsándolos del espacio local:

E: ¿Y por acá por la zona hubo algún saqueo?

R: No, no. No acá, no.

E: ¿En otros barrios de por acá?

R: No que yo me haya enterado, no. Acá no hay cadenas (...) Acá no pasó nada. No pasó nada, no... Acá es todo tranquilo. Hasta hoy $(. .$.

E: ¿Había rumores de saqueos y eso?

R: No, no, no. Ya te digo, acá toda la gente, la mayoría de la gente somos todos laburantes. Acá son todos laburantes (...)

E: ¿Y entre los vecinos, se decía algo? 
R: No, no, no. Yo te digo, que yo, por ejemplo, es como te vuelvo a recalcar. Yo vengo de mi laburo, venía, pum, abro el portón, entro acá adentro, cierro, me baño, vengo acá, me tomo unos mates (Juan Carlos, jubilado, 59 años).

El perfil de Juan Carlos marca cierta posición extrema -en la que el saqueo directamente es negado- tanto como interesante. Como se mencionó, en las proximidades del barrio existe una avenida en la que diferentes comercios -entre pequeños y medianos- fueron saqueados. Además, los relatos de otros entrevistados suelen focalizarse en hechos curiosos en relación a ellos, que permiten recuperar de qué establecimientos se trató. Sin embargo, en el recuerdo de Juan Carlos el saqueo se encuentra plenamente expulsado: ni en su propio barrio, ni en los cercanos; siquiera a través de rumores se tuvo contacto con los saqueos. Esta conclusión aparece ligada tanto a lo laboral como -y en relación al trabajo- lo espacial.

Juan Carlos recupera la experiencia legítima del fragmento anterior a través de la condición de trabajador (la mayoría de la gente somos todos laburantes). Como en la otra cita, ese rasgo se vincula a la tranquilidad, de manera tal que trabajar garantiza la calma y esa actitud lleva a la ausencia de saqueos. Ente encadenamiento -ya implícito en su referencia al contexto socio-económico- se expande ahora sobre las sociabilidades locales, de modo tal que su barrio es, ahora, un territorio integrado por personificaciones homólogas al enunciador: al igual que él, son trabajadores.

Hacia el final, esa presentación-de-sí explicita una espacialidad: una jornada laboral extensa es lo propio de los trabajadores; ella conlleva, intrínsecamente, un uso mínimo de los espacios comunes locales (yo vengo de mi laburo, abro el portón, entro acá adentro, cierro). El enunciador encarna esta rutina, consagrada como ejemplo de prácticas comunes a los vecinos. Los rasgos que convierten a Juan Carlos en garante de sus palabras son, entonces, paradójicos: su ethos está marcado por una sociabilidad local asumida como escasa pero es justamente ese carácter -compartido con sus vecinos- que tornan imposible al saqueo. Aún tematizado como poco apropiado para recordar, este vínculo particular con la espacialidad del barrio elaboran la veracidad de la memoria.

La posición del enunciador destierra la crisis del barrio, incluso la traslada al exterior de las zonas lindantes. Su experiencia se constituye en una ligazón parcial, apartada con el acontecimiento. La personificación del saqueador se caracteriza por un fuerte distanciamiento respecto al sujeto, que lo ubica en su ausencia: el entrevistado los define como no trabajadores, como carentes de un modo legítimo de sobrellevar la crisis y, además, como no presentes en el barrio. Tan alejados, los saqueadores devienen imposibles.

\subsection{El saqueo desde una espacialidad replegada}

La inexistencia (representada) del saqueo imbrica las dos variables de corte en un sentido particular: la crisis -vivida- no incluyó el desempleo y los usos del espacio suponían un acuciado predominio de lo individual/ familiar - no al margen, ciertamente, de esa estabilidad laboral. Esta primera construcción de la memoria se distancia del saqueador al punto de negar su presencia.

Desde luego, esta modalidad de evocación no es la única y otras elaboraciones del recuerdo pueden ser reconocidas al configurarse esas dos variables de maneras disímiles. Agustina tenía 30 años al momento de ser entrevistada. Ella siempre realizó trabajos de cuidado en su casa. Su esposo tiene una trayectoria relativamente estable, con más de 10 años en una fábrica. Sin embargo, a comienzos de los 2000, su familia y la de su pareja debieron recurrir a programas de asistencia y empleos eventuales. Su relato elabora el padecimiento de la crisis -que destaca en relación al primer entrevistado- pero desde la estabilidad obtenida en los años posteriores de recuperación económica.

$\mathrm{Al}$ ser consultada por el recuerdo de la crisis, rápidamente hilvana una memoria en la clave de una situación violenta y descontrolada:

Justamente el otro día le estaba mostrando a mi hijo, que nos pusieron en el Facebook un video de lo que fue el 2001 y le decía -y me agarró una angustia- y me dice: “¿Por qué lloras?” ”Papito vos porque eras bebé, no lo viviste: ¿sabés qué feo es ver 
cómo la gente se... mataba? (...) No sé si era tanto por necesidad o porque ya la viveza de cada uno, ¿no? (...) Mi vieja trabajaba en capital y nosotros vivíamos acá, y mi mamá no pudo llegar porque habían cortado todo, no pasaba ningún colectivo para Provincia, y se tuvo que quedar ahí en Capital (Agustina, ama de casa, 30 años).

En el relato de Agustina, el carácter generalizado se imbrica fuertemente con la participación del enunciador: la crisis se constituye en un fenómeno de alto impacto, con el que no se puede mantener una distancia en clave de tranquilidad o calma. El 2001 es anclado en la memoria de una experiencia traumática, que sigue impactando en el presente (me agarró una angustia).

Empero, sería erróneo concluir que todas las personificaciones de la cita guardan los mismos rasgos, homólogos, en última instancia, a los del enunciador. Por el contrario, se extiende el contraste entre los propios - un nosotros en clave familiar, la madre que no puede volver a su casa- $y$ los distantes -involucrados en conductas de cierta (representada) inmoralidad (se mataba; viveza).

El efecto es, nuevamente, una segmentación entre experiencias de la crisis -válidas e ilegítimas- pero que opera a partir de núcleos temáticos diferentes al perfil anterior. La distancia ya no se presenta entre aquellos calmos y los desesperados sino entre los próximos refugiados, recluidos y un conjunto de afectados por la crisis que accionan violentamente. Esta contraposición anticipa un posicionamiento respecto a la figura del saqueador en clave de fuerte distanciamiento aunque bajo una representación ausente en el primer entrevistado:

\footnotetext{
Mirábamos acá, subimos ahí al techo, nos subimos ahí y mirábamos como pasaban corriendo (...) Mi hermana decía: "Si, porque, ¿viste que dijeron que uno de allá llevó gente para rob... para saquear”: Así viste, pero cuando no conoces, te decían, vino de allá, de allá, no los conocés pero siempre se escucha el rumor ese que vino uno de acá. Y el de acá que está en la [calle] 823 dice que fueron los pendejos, pero entraron directamente a lo que es vino, cerveza, después la gente misma, al entrar uno o dos, ya entraron después todos, la gente del barrio dicen que habían entrado. Pero acá el mercado no se llegó a robar ahí, saquear ahí, pero se veía en lugares [que] rompieron todo, robaron todo (Agustina, ama de casa, 30 años).
}

Ciertamente, destacan los rasgos inmorales de quien participa en los saqueos: la asimilación al robo y el destrozo, los rumores respecto al carácter organizado y planificado de la acción y, finalmente, la predilección por bebidas alcohólicas. Si en la primera cita la referencia a la necesidad todavía se encontraba implícita, ahora se desvanece bajo el peso de estas motivaciones, más próximas al delito que a la falta de alimentos. Como ocurría con Juan Carlos -el perfil anterior-, la descripción de actitudes ilegítimas en contextos de crisis actualiza representaciones ligadas a formas de distinción, en este caso vía el rechazo a consumos hedonistas, encarnados simbólicamente en jóvenes de sectores populares.

Todos estos elementos prolongan la tematización del contexto socio-económico de la crisis: nuevamente, la personificación del saqueador -fuertemente lejana en relación a la entrevistada- recrea la escisión del momento de la crisis entre una serie de prójimos legítimos y ciertas alteridades impugnadas. Ahora bien, como con el primer entrevistado, el sentido de la espacialidad del saqueo no constituye una dimensión menor. La siguiente cita la describe, junto con otros elementos recurrentes en estas memorias:

\footnotetext{
¿Qué pasó? No podés salir ni a la puerta de tu casa. Yo le decía eso a mi hijo (...) gracias a Dios no duró mucho el estado de sitio, pero era feo porque vos no podías salir a la calle porque te levantaban, te llevaban preso, te cagaban a palos, se decía (...) El tema también ese de que vino, cuando supuestamente, esa psicosis que venían los de Fuerte Apache (...)

$\mathrm{E}:$ ¿Vos sabes que hicieron los demás vecinos frente a los saqueos?

R: No, creo que acá cada uno se quedó en su casa, que no salió (...) Viste cuando tenés miedo de (...) la situación de querer salir y que te quieran robar o te lleven preso a vos o que te caguen a palos, porque no sabés. Llegaba las ocho de la noche y directamente ya estábamos todos adentro y no salía nadie. Estábamos todos acá sentados, fue en el verano, así que era estar sentada acá mirando los que pasaban y a la tarde ya pasaba la policía. (Agustina, ama de casa, 30 años).
}

Si bien acompaña la elaboración de una figura del saqueador como lejana, la espacialidad concebida no es la del primer entrevistado. Las memorias de Juan Carlos y Agustina comparten una acepción de lo espacial como refugio. Empero, mientras que en el primero lo doméstico conformaba el reposo de una rutina laboral válida (una jornada extendida fuera del barrio), en la cita de Agustina, el hogar deviene el sitio de una retirada 
frente a diversos peligros, que remiten tanto a la acción de los saqueadores como de la policía. El rol de los rumores actualiza la presencia fantasmal de los saqueos: la supuesta llegada de saqueadores provenientes de un barrio sumamente lejano -siquiera ubicado en la Zona Sur del conurbano- suele ser mencionada por los entrevistados, exponiendo el recurso a alteridades estigmatizadas en la representación del saqueador.

Este anclaje en el sitio del barrio configura la experiencia bajo una modalidad particular, en la que la espacialidad participa de la formación del recuerdo. En efecto, mientras que las facetas políticoinstitucionales de la crisis rara vez son mencionadas por los entrevistados cuando se interroga acerca del 2001 -en el caso de esta entrevistada están ausentes por completo-, los saqueos sí resaltan, aun cuando en el perfil anterior se los expulsaba del barrio. En el caso de Agustina, sus usos de la espacialidad también son eminentemente individual/familiares aunque no involucran -como con el otro entrevistado- una salida diaria a partir de una jornada laboral extensa en zonas más céntricas. Su perfil da cuenta de cómo esa apropiación de lo local se conjuga con una memoria que enfatiza esa instancia de repliegue hacia lo doméstico, resaltando el abandono -transitorio, bajo el miedo- de los espacios representados como comunes (calles).

La espacialidad del saqueo resulta ubicua: es próxima, en cuanto se presenta en un sitio cercano; lejana en cuanto se encontraba -en el 2001 - plagada de alteridades peligrosas. En consecuencia, el sujeto experimenta el saqueo, está inmerso en lo que ocurre, pero desde la posición de un observador que es ahora testigo de una amenaza. El umbral entre lo doméstico y el espacio público se convierte en una frontera con dichas alteridades, policías y saqueadores pero en especial estos últimos.

Una experiencia relatada en clave traumática (por el saqueo y por la crisis económica), ocurrida en un espacio próximo y apropiado -solo que desde una forma específica, individual, si se quiere, privada- garantiza la fuerza del recuerdo cuanto marca los contornos de su reconstrucción desde el presente: la distancia con la personificación del saqueador se profundiza y agiganta, sobreviviendo integrada en un acontecimiento que impone encontrarle un sentido. El rol de testigo -presente y apartado, replegado; participante en su distancia con los demás- marca las características de este experiencia cuanto su sutura simbólica, a partir del distanciamiento con esos otros protagonistas.

\subsection{Saqueadores (un tanto más) próximos}

A pesar de contener representaciones divergentes de la crisis, los primeros dos perfiles definen a la figura del saqueador en términos similares. La tercera entrevistada -Beatriz, de 50 años al ser entrevistada- exhibe otro tipo de trayectoria laboral y de usos del espacio. Junto con su pareja, Beatriz tuvo diversos empleos eventuales, ninguno de ellos en condición de formalidad, imprimiéndole una fuerte inestabilidad a una trayectoria definida por ella misma como de desempleo prolongado. En paralelo, integró distintas organizaciones territorialmente ancladas (centros comunitarios) y su esposo tuvo cierto rol de mediador en programas de asistencia (cooperativas). De esta manera, un plano laboral más inestable concuerda, en su caso, con usos de la espacialidad local en clave organizada, excediendo las interacciones con familiares o personas cercanas. $\mathrm{Si}$ bien este perfil representa al saqueador desde el distanciamiento, recurre a otros rasgos, que matizan la lejanía.

En los dos entrevistados anteriores, el contexto de crisis económica podía encarnarse en el enunciador o en otros aunque, en ambos casos, operaba a partir de una fuerte delimitación entre modos legítimos y no legítimos de atravesar el momento. La memoria de Beatriz no puede ser resalta el padecimiento del momento pero -en contraste con la anterior entrevistada- tematiza a la crisis como una experiencia común, si bien particular:

La tuve que pelar sola. Mucha gente estaba muy mal. Mucha gente estaba muy mal (...) Mucha gente estaba pasando muchas necesidades y trataba de no demostrarlo puertas afuera. Y el que trataba de salir a pedir, lo hacía minuciosamente. A ocultas. (Beatriz, desocupada, 50 años). 
En la trayectoria laboral de Beatriz, el 2001 constituye un punto extremo de vulnerabilidad en el marco de una afiliación laboral (Castel, 2010) de por sí precaria. En la cita, la crisis tiene un anclaje individual, que destaca el relativo aislamiento de cada protagonista. El sentido de esa coyuntura no opone la experiencia propia a la de los demás: establece una suerte de soledad generalizada, que encuadra a la descripción en el predominio de la proximidad. Cada uno se encuentra solo, padeciendo el momento, pero las experiencias son asimilables, se las comparte a nivel de su representación, colocando en el centro un criterio de legitimidad fundado en la necesidad.

Esta tematización de la crisis no se ajusta, empero, a las acciones de la propia entrevistada, quien también dice haber adoptado diferentes estrategias, todas ausentes en ese fragmento: acudir a comedores comunitarios, establecer redes con vecinos para obtener empleos eventuales, organizar actividades (bingos) con familiares y conocidos... En la trayectoria de Beatriz, estos usos colectivos del espacio continuaron, con modificaciones, en los años posteriores y se prolongaron hasta el momento de la entrevista sin implicar vulnerabilidades tan extremas como las del 2001. Esta falta de concordancia entre parte de la experiencia y su significación resalta el papel de la necesidad como síntesis del momento pero también como rasgo de quienes personifican la memoria, situándolos en un plano de proximidad respecto al enunciador. La definición en la clave como necesitados acompaña una evaluación del saqueador ausente en los dos perfiles anteriores.

A la crisis vivida como una suerte de común soledad corresponde, así, otra descripción del saqueador, acompañada de un anclaje espacial diferente:

Los pibes de acá vinieron, pusieron... Se plantaron en el medio de la calle: "se va a ir a tomar... Se va a ir a saquear el supermercado, no hay para comer, y...”. Se juntaron los pibes y ya se empezaron a salir la gente, y ahí en manada (...) Son los hijos de los vecinos (...) porque no tenían trabajo, no le daban trabajo. Y la necesidad era mucha. (Beatriz, desempleada, 50 años).

La necesidad vuelve a destacar como potencialmente legitimante de la acción: los participantes se encontraban sin poder alimentarse, carecían de empleo -actualizando el contexto del fragmento anteriory al iniciar el saqueo, otros los siguieron. La narración contiene etapas y prácticas similares al relato de la entrevistada del perfil anterior: nuevamente, los rumores, la juventud de los protagonistas y la realización del saqueo en las inmediaciones aparecen como núcleos temáticos de importancia. No obstante, en la memoria de Beatriz, se concilian para describir el resultado un tanto esperable del contexto económico general, marcado por la falta de trabajo y las dificultades para adquirir siquiera bienes de primera necesidad; en el caso de Agustina -la entrevistada anterior- personificaciones similares (pibes) acaban robando bebidas alcohólicas.

¿Cuál es el anclaje espacial de esta memoria? La cita se encuentra lejos del repliegue hacia lo doméstico del segundo perfil y, por supuesto, de la inexistencia local del saqueo del primero. La posición del enunciador vuelve a ser la de un testigo: ella observa a los necesitados tomar la decisión de saquear, retoma sus palabras incrustándolas en su propia narración. Y, finalmente, al precisar la figura de los saqueadores, los define a través de una espacialidad que constituye proximidad: "hijos de los vecinos" los transforma en alteridades cercanas, conocidas y, a través de ese posicionamiento, potencialmente justificables en su acción. En esta operación, la perspectiva del testigo es bien diferente a la entrevistada anterior: en vez de estar refugiada en su casa, Beatriz se sitúa en la calle, garantizando su relato a través de un conocimiento que se asume de primera mano en relación a las palabras de los saqueadores y las motivaciones tras ellas.

Podría parecer, entonces, que la memoria de Beatriz los posiciona en la proximidad. Sin embargo, la potencial validación a través de la necesidad no lleva a la identificación con quiénes saquearon, como puede notarse en el siguiente fragmento:

E: ¿Y cómo era andar por el barrio durante el saqueo? ¿Era seguro, tenías miedo?

R: No, no... Si vos salías no tenías que tener nada bueno, y aparte te pegaban por nada. Porque al no tener plata, la gente tenía mucha necesidad. (Beatriz, desempleada, 50 años). 
La apelación a la condición de necesitados persiste, aunque compensada por una expectativa de peligro: los protagonistas podrían trocar en ladrones. Ahora bien, el camino inverso también es mencionado: la falta de dinero explica, en la cita, el comportamiento de quienes saquearon. Bajo esta ambigüedad se configura el distanciamiento, que impugna en última instancia una memoria fundada en la proximidad o en la participación del propio enunciador en los saqueos. Beatriz no se ubica a sí misma en ese rol: por el contrario, elabora una diferencia entre su acción del momento y la de los demás. Recurre a matices fundados en la necesidad -que insertan cierta proximidad respecto al saqueador- pero el predominio de la lejanía es infranqueable: las variaciones en cómo se representa a los participantes del saqueo se enmarcan, en todos los entrevistados, en la primacía del distanciamiento.

La necesidad introduce un criterio moral ausente en los dos perfiles anteriores, que se imbrica con la evocación del impacto de la crisis en la propia trayectoria y en la representación de los saqueadores. Así, entre la situación socio-económica gravosa y desesperante se replica-siempre en el plano del sentido- entre los vecinos y anticipa una explicación del saqueo que disminuye su impugnación. Al mismo tiempo, la participación de la entrevistada en organizaciones ancladas localmente favorece una representación de la espacialidad como peligrosa -al momento del saqueo- pero habitada, en la que se transita y en la que un fenómeno general afecta a todos de forma semejante. Testigo y protagonista del saqueo ocupan un mismo espacio (la calle). La distancia no se anula, la identificación con el saqueador no se produce pero sí se lo contextualiza.

\section{CONCLUSión: LOS MÚLTIPLES CRUCES ENTRE EL ESPACIO Y LA MEMORIA}

Entre las múltiples dimensiones de la crisis del 2001, las continuidades y cambios en el modelo económico, las formas de movilización política y la crisis de representación quizá recibieron mayor atención por parte de la bibliografía (Adamosky, 2016; Ozarow, Levey \& Wylde, 2016). Sobre las memoria elaborada en los años posteriores, se ha sostenido que la identifcación del 2001 como un "infierno" asimilaba buena parte de sus movilizaciones a acciones inconducentes (Adamosky, 2016). Si bien en este trabajo se ha puesto el foco en los saqueos, la centralidad que ocupan en las representaciones de los entrevistados acerca del 2001 quizá imponga considerar mayores distancias entre las dimensiones político-institucionales de la crisis y la memoria elaborada por sectores populares del Gran Buenos Aires.

Entre los habitantes de los dos barrios tomados como caso de estudio en el Municipio de Quilmes, la evocación de saqueos se concentró en la figura del saqueador, su accionar y su (falta de) legitimidad. Trabajos llevados a cabo en otros municipios del conurbano (Nuñez, 2015) dieron cuenta de una construcción de la memoria similar, aportando cierta evidencia de la posible transferibilidad de los resultados más allá del caso de estudio indagado.

Sea como fuere, el modo de representar a la figura del saqueador entre los entrevistados está lejos de ser homogéneo. Por el contrario, se encuentra doblemente segmentado. El impacto del 2001 en la trayectoria laboral (familiar o personal) y los usos del espacio local inciden sobre la definición del recuerdo. Mientras que el distanciamiento con saqueador se matiza entre entrevistados que atravesaron situaciones de desempleo y realizan usos colectivos del espacio, aquellos que pudieron conservar su trabajo y tienen un vínculo con el espacio local individual/familiar tienden a profundizar la impugnación de quienes participaron del saqueo.

La espacialidad no contribuye únicamente como escenario del recuerdo de lo ocurrido, como si solo diera un anclaje al sentido del saqueo. Por el contrario, integra la elaboración de la memoria: los usos del espacio del barrio proveen de diversas condiciones de posibilidad del recuerdo del 2001, que explica tanto el foco en el contexto socio-económico de la crisis como diferentes modalidades de evocación del saqueo y de quienes lo realizaron.

Así, la memoria del 2001 resulta atravesado por alteridades del presente y del pasado, por definiciones de lo aceptable y de lo inmoral así como usos pretéritos y actuales del espacio local. 


\section{REFERENCIAS}

Adamosky, E. (2016). Epílogo. En Ozarow, D., Levey, C., \& Wylde, C. De la crisis del 2001 al kirchnerismo: cambios $y$ continuidades. Buenos Aires: Prometeo, pp. 293-300.

Auyero, J. (2007). La zona gris. Buenos Aires: Siglo XXI

Basualdo, E. (2011). Sistema politico y modelo de acumulación. Buenos Aires: Atuel

Castel, R. (2010). El ascenso de las incertidumbres. Trabajo, protecciones, estatuto del individuo. México: Fondo de Cultura Económica.

Gordillo, M. (2017). La Violencia Anunciada. El Ruido de las Ollas Vacías en 2001. En Di Meglio, G., Serulnikov, S. La Larga Historia de los Saqueos en Argentina, Buenos Aires: Siglo XXI, pp. 201-226.

Izaguirre, I. y Aristizabal, Z. (1988). Las tomas de tierras en la zona sur del Gran Buenos Aires. CEAL: Buenos Aires.

Halbwachs, M. (2004). La memoria colectiva. Zaragoza: Prensas universitarias.

Jelin, E. (2002). Los trabajos de la memoria. Madrid: Siglo XXI.

Jodelet, D. (1984). La representación social. Fenómeno, concepto y teoría, en Moscovici. S., Pensamiento y vida social (pp. 469-494). Barcelona: Paidós.

Lefebvre, H. (2013). La producción del espacio. Madrid: Capitán Swing.

Merklen, D. (2010). Pobres Ciudadanos. Buenos Aires: Gorla.

Neufeld, M. R., \& Cravino, M. C. (2007). Entre la hiperinflación y la devaluación: "saqueos" y ollas populares en la memoria y trama organizativa de los sectores populares del Gran Buenos Aires (1989-2001). En Resistiendo en los barrios. Acción colectiva movimientos sociales en el Area Metropolitana de Buenos Aires. Prometeo/Universidad de General Sarmiento, Los Polvorines, Argentina, 13-38.

Nuñez, J. (2015). Crisis, barrio y saqueadores, en torno a la memoria de los saqueos del 2001 en sectores populares del Gran Buenos Aires. En 8vas. Jornadas de Jóvenes Investigadores, Instituto de Investigaciones Gino Germani, Buenos Aires, Argentina. Recuperado de http://jornadasjovenesiigg.sociales.uba.ar/wp-content/uploads/sites/ 107/2015/04/eje6_Nuez.pdf

Onuch, O. (2016). 'Es la economía boludo' ¿o no es así? El rol de la crisis política en la movilización masiva: el caso de Argentina en el 2001. En Ozarow, D., Levey, C., \& Wylde, C. De la crisis del 2001 al kirchnerismo: cambios $y$ continuidades (pp. 121-149). Buenos Aires: Prometeo.

Ozarow, D., Levey, C., \& Wylde, C. (2016). De la crisis del 2001 al kirchnerismo: cambios y continuidades. Buenos Aires: Prometeo.

Ossona, J. (2017). Los Saqueos en Lanús y en Villa Fiorito del 19 de Diciembre de 2001. En Di Meglio, G., Serulnikov, S. La Larga Historia de los Saqueos en Argentina (pp, 227-246). Buenos Aires: Siglo XXI.

Pereyra, S. (2008). ¿La lucha es una sola?. Buenos Aires: Universidad nacional de General Sarmiento.

Prevot-Schapira, M. F. (2009). Apuntes de Moreno. Apuntes de Investigación del CECYP, №16, 99-111.

Ricoeur, P. (2004). La memoria, la historia, el olvido. Buenos Aires: Fondo de Cultura Económica.

Serulnikov, S. (2017). Como si estuvieran comprando: los saqueos de 1989 y la irrupción de la nueva cuestión social. En Di Meglio, G., Serulnikov, S. La Larga Historia de los Saqueos en Argentina (pp. 137-176). Buenos Aires: Siglo XXI.

Schuster, F., Pérez, G., Pereyra, S., Martín Armelino, M. B., Larrondo, M., Patrici, N., Varela, P., Vázquez, M. (2002). La trama de la crisis. Buenos Aires: Universidad de Buenos Aires.

Svampa, M., Pereyra, S. (2003). Entre la ruta y el barrio. La experiencia de las organizaciones piqueteras. Buenos Aires: Alianza.

Thompson, E. P. (1979). Tradición, revuelta y consciencia de clase: estudios sobre la crisis de la sociedad preindustrial. Barcelona: Crítica. 


\section{Notas}

1. Schuster, F. et al, mencionan la existencia de saqueos en las provincias de Buenos Aires, Santa Fe, Río Negro, Mendoza, Corrientes y Entre Ríos (Schuster, F. et al, 2002). La recopilación de Gordillo agrega las de Tucumán, Neuquén, Córdoba, San Juan, Santiago del Estero, Corrientes y CABA (Gordillo, 2017).

2. Ciertamente, sería deseable conocer qué tanto esa memoria se encuentra diferenciada según la participación en los saqueos. Empero, en tanto acción ilegal -y representada como inmoral- muy rara vez se obtiene del entrevistado una referencia a su propia participación en los saqueos, impidiendo un abordaje metodológico en esa clave.

3. Seminario de la Carrera de Sociología (UBA) "Procesos de (des)encaje y movimientos sociales: reconfiguraciones de identidades colectivas”. Estudiantes: Carolina Bruzuela, Mercedes Maidana, Paula Martínez, Juan Pablo Palmucci y Ana María Rodríguez. Equipo docente: María Maneiro, María Carla Bertotti y Santiago Nardin.

4. Todos los nombres de los entrevistados fueron cambiados para preservar su anonimato. 